\title{
Fórmula e utopia: o movimento internacional da educação nova
}

(Formula and utopia: the international new education movement)

\author{
Diana GONÇALVES VIDAL \\ Rafaela SILVA RABELO \\ Universidade de São Paulo, Brasil
}

\begin{abstract}
RESUMO: Partindo da interrogação sobre a pregnância de ideias e práticas associadas ao repertório da Educação Nova em discursos pedagógicos atuais e operando com as noções de utopia e fórmula, 0 artigo se debruça sobre três iniciativas, consideradas como hubs, ou seja, como pontos de conexão, encontro e passagem de educadores. São elas: a New Education Fellowship (NEF), que nos países latinos ficou conhecida como Ligue Internationale pour I'Éducation Nouvelle (LIEN), e a ação sistemática de formação de, ao menos, dois institutos internacionais, ligados ao Teachers College e ao Institute Jean-Jacques Rousseau. Outras ações, como a Progressive Education Association (PEA), o Bureau International d'Éducation (BIE) e o Bureau International des Ecoles Nouvelles (BIEN) emergem também compondo a argumentação. 0 objetivo é explorar redes que, ao mesmo tempo, consolidaram propostas associadas à Educação Nova em vários países, constituídas como uma utopia pedagógica, e alargaram os significados a ela atribuídos, evidenciados pelo mosaico terminológico que cerca o movimento.
\end{abstract}

PALAVRAS-CHAVE: Teachers College, Instituto Jean-Jacques Rousseau, Progressive Education Association, Bureau International d'Éducation, História conectada

ABSTRACT: The article examines the impact of the ideas and practices of the New Education movement on pedagogical discourse today using the concepts of utopia and formula. The analysis focuses on three hubs of connection and encounter between educators in the twentieth century: the New Education Fellowship (known in Latin countries as the Ligue Internationale pour l'Education Nouvelle), and the systematic training initiatives of the Teachers College and the Jean-Jacques Rousseau Institute. Other initiatives, such as the Progressive

\footnotetext{
${ }^{1}$ A discussão aqui proposta é 0 resultado de pesquisas vinculadas a diferentes projetos: "Educação transnacional: (des)conexões entre Brasil e a New Education Fellowship (1920-1948)" (Processo FAPESP 2015/06456-1); "Perscrutando o papel da Progressive Education Association na circulação da New Education Fellowship no Brasil (1920-1940)" (Processo FAPESP 2016/07024-0); "Saberes e Práticas em Fronteiras: por uma história transnacional da educação (1810-...)" (Processo FAPESP 2018/26699-4). Integra ainda o projeto "Múltiplas estratégias de escolarização da infância: contrastes de uma história transnacional da educação" (CNPq, processo 305639/2016-1).
} 
Education Association, the International Bureau of Education and the International Bureau of New Schools, are also discussed within this context. The aim of the study is to analyse the networks responsible for promoting the spread of the utopian pedagogical ideas of New Education in different countries and broadening its interpretation, as reflected in the terminological mosaic associated with the movement.

KEYWORDS: Teachers College, Jean-Jacques Rousseau Institute, Progressive Education Association, Bureau International d'Éducation, Connected history

\section{Introdução}

A produção acadêmica sobre a Educação Nova é vasta e internacional. Dois dossiês publicados na Paedagogica Historica evidenciam estas dimensões. 0 primeiro, lançado em 2006, coligiu uma seleta de trabalhos apresentados no $26^{\circ}$ Congresso da International Standing Conference for the History of Education, ocorrido em Genebra, e dedicado ao tema L'Education nouvelle, genèse et metamorfoses. ${ }^{2} 0$ segundo, saído em 2009, foi organizado por Rita Hofstetter e Bernard Schneuwly. ${ }^{3}$ Em ambos manifesta-se a proeminência da problemática para investigações efetuadas no continente americano, Europa e 0ceania, particularmente no que concerne ao período entre 1920 e 1940. Para Hofstetter e Schneuwly, ela decorre da difusão mundial do movimento e pode ser aquilatada pelas várias denominações que este assumiu em diversos países, como New Education, Progressive Education, Reformpädagogik, Escola Nova, Escuela Nueva, educação funcional, escola ativa, às quais poderíamos agregar ainda Éducation Nouvelle e École Nouvelle.

No entanto, a frequência com que a questão emerge no debate acadêmico destoa ou converge, segundo a perspectiva adotada, com o grau de generalidade com que o termo é evocado nos trabalhos. Destoa se considerarmos que tal insistência deveria repercutir em um delineamento robusto do problema. Converge se concordamos com a análise de Daniel Hameline ${ }^{4}$ quando afirma que a fortuna de uma fórmula é tanto maior quanto mais imprecisa sua definição, gerando um território neutro capaz de acomodar diferentes e, mesmo, divergentes aproximações. A avaliação remete a um alerta: para efeito de argumentação e corroborando a noção de fórmula, optamos por utilizar, neste texto, provisoriamente, a expressão Educação Nova, apesar de reconhecermos que as mudanças de denominação implicam também em alterações de sentido, construídos social e historicamente.

\footnotetext{
${ }^{2}$ Charles Magnin and Rita Hofstetter, "Education nouvelle et changements éducatifs: éléments de définition et pesées d'une influence", Paedagogica Historica 42, no. 1-2 (2014): 1-14.

${ }^{3}$ Rita Hofstetter and Bernard Schneuwly, "Contrasted views of New Education on knowledge and its transformation. Anticipation of a new mode or ambivalence?", Paedagogica Historica 45, no. 4-5, (2009): 453-467.

${ }^{4}$ Daniel Hameline, L'école active. Textes fondateurs (Paris: PUF, 1995).
} 
Um elemento parece-nos fundamental nos contornos da problemática e dele derivam todos os demais. De acordo com Watras ${ }^{5}$ e Brehony, ${ }^{6}$ a propagação da Educação Nova nos anos 1920 e 1930 coincidiu com a criação dos Departamentos de Educação em diversas Universidades do mundo. Foi o caso do Teachers College associado à Columbia University (TC/CU) em 1923; do Institute Jean Jacques Rousseau à Université de Genéve (IJJR/UG) em 1929; do Institute of Education à University of London (loE/UL) em 1930, para citar poucos exemplos. Da mesma forma, no Brasil, os Institutos de Educação do Rio de Janeiro e de São Paulo, surgidos em 1932 e 1933, respectivamente, incorporaram-se às Universidades do Distrito Federal, em 1935, e de São Paulo, em 1934. ${ }^{7}$ Superava-se, então, o caráter mais diretamente prático da formação de professores nas Escolas Normais e almejava-se a produção de uma verdadeira ciência ou ciências da educação, com protocolos de legitimidade oferecidos pelo campo acadêmico.

Ainda nos dias atuais, a pregnância de autores vinculados à Educação Nova no discurso pedagógico e a partilha de um repertório de preocupações e temas, aproximam docentes universitários, pesquisadores e educadores de distintos países. Atualizadas e, muitas vezes, descontextualizadas historicamente, propostas como protagonismo infantil, método de projetos, centros de interesse, professor como mediador, educação para democracia, dentre outras, sobrevivem como ideais a atingir ou como práticas apenas pontualmente instauradas e dificilmente replicáveis, configurando o que poderíamos chamar, reiterando Fernando Vidal, ${ }^{8}$ de faces de uma utopia político-pedagógica que despontou no entreguerras.

Duas iniciativas, surgidas nos anos 1920, com grande impacto no debate educacional, podem ser identificadas na gênese da circulação internacional de teorias e experiências relacionadas à Educação Nova. A criação da New Education Fellowship (NEF), em 1921, que nos países latinos ficou conhecida como Ligue Internationale pour l'Éducation Nouvelle (LIEN) ou simplesmente por Liga (evento que deu origem a este dossiê comemorativo organizado pela revista Sarmiento), e a ação sistemática de formação de, ao menos, dois grandes institutos internacionais, ligados ao Teachers College (TC) e ao Institute Jean-Jacques Rousseau (IJJR). Outras ações, como a Progressive Education Association (PEA), o Bureau International d'Éducation (BIE) e o Bureau International des Ecoles Nouvelles (BIEN), se entrelaçam a esse movimento internacional e consolidam as redes constituídas, unindo nações ao redor do mundo.

\footnotetext{
5 Joseph Watras, "The New Education Fellowship and UNESCO's programme of fundamental education", Paedagogica historica 47, no. 1-2 (2011): 191-205.

${ }^{6}$ Kevin J. Brehony, "A new education for a new era: the contribution of the conferences of the New Education Fellowship to the disciplinary field of education 1921-1938", Paedagogica Historica 40, no. 5-6 (2004): 733-55. ${ }^{7}$ Cf. Diana Gonçalves Vidal e Rafaela Silva Rabelo, "A criação de Institutos de Educação no Brasil como parte de uma história conectada da formação de professores", Cadernos de História da Educação (online) 18, no. 1 (2019): 208-220.

${ }^{8}$ Fernando Vidal, “L'éducation nouvelle et l'esprit de Genève”. Equinoxe, no. 17 (1997): 98. Conferir também Diana Vidal, Rafaela Rabelo, Ariadne Ecar, and Fernanda Franchini, "Democracia, escola e infância: legado e utopia escolanovista", in Democracia, escola e infância, ed. Carlota Boto e Julio Groppa Aquino (São Paulo: FEUSP, 2019), 107-22.
} 
Diversamente do que consideram Rita Hofstetter e Bernard Schneuwly, que se valem dos conceitos de centro e periferia ${ }^{9}$ para abordar a problemática, preferimos acionar a categoria $h u b,{ }^{10}$ ponto de conexão de redes, local de encontro e passagem. A inflexão é importante. Hub consiste em uma espécie de nó, que se situa no meio de várias trajetórias. Não é necessariamente seu ponto inicial ou final, mas o ponto de contato. Portanto, não é condição ou resultado, mas convergência. A perspectiva coloca em relevo 0 significado das interações pessoais e dos lugares de encontro. Nesse sentido, concordamos com Peter Burke ${ }^{11}$ quando assevera que as análises alicerçadas na relação centro e periferia correm o risco de apenas considerar os processos de difusão de conhecimento que partem do centro, sem dar relevo aos fluxos que saem da periferia em direção ao centro.

A reflexão dá substância à categoria rede/network. Simultaneamente explicita a opção por uma história conectada da educação e o foco na circulação internacional de sujeitos educacionais. No que concerne ao primeiro ponto, de acordo com Eckhardt Fuchs, ${ }^{12}$ "redes são relações condensadas e intencionais entre atores confinados a espaços específicos". Importa na sua análise, avaliar "o significado, a forma e a duração de sua existência, bem como a intensidade, frequência, balanço, proeminência e velocidade dos contatos, trocas e transferências". Lembra, ainda, que as redes têm maneiras específicas de governança ou de coordenação de ações, podendo organizarem-se formal ou informalmente.

Nesse processo valorizam-se as agências dos sujeitos educacionais, combinando enfoques macro e micro, em histórias múltiplas, enredadas em realidades constituídas em diferentes escalas, com ênfase no "caráter crucial, por vezes determinante, que as iniciativas locais e particulares", no dizer de Sanjay Subrahmanyam, ${ }^{13}$ jogam na conformação dos saberes e práticas, tidos como matrizes. São esses circuitos vários que o enquadramento em uma história conectada da educação almeja captar, escapando a uma visão dualista, por meio da atenção às "paisagens misturadas, muitas vezes surpreendentes e sempre imprevisíveis", como quer Serge Gruzinki, ${ }^{14}$ que as fontes oferecem.

Para discorrer sobre estas questões, 0 artigo está organizado em três partes que se complementam com esta introdução e uma conclusão. Na primeira parte, exploramos a

\footnotetext{
${ }^{9}$ Hofstetter, and Schneuwly, "Contrasted views of new education".

${ }^{10} \mathrm{Em}$ teoria das redes, hubs consistem em nós com várias conexões. Os nós, por sua vez, podem designar indivíduos, grupos, corporações ou qualquer tipo de coletivo. Albert-László Barabási, Linked: how everything is connected to everything else and what it means for business, science, and everyday life (New York: Plume, 2003); Silvia Portugal, "Contributos para uma discussão do conceito de rede na teoria sociológica", Oficina do CES n ${ }^{0}$ 271, Março, 2007.

${ }^{11}$ Peter Burke, História social do conhecimento (Rio de Janeiro: Zahar, 2003$), 57$.

${ }^{12}$ Eckhardt Fuchs, "Networks and the History of Education", Paedagogica Historica 43, no. 2 (2007): 187. No original: "Networks are condensed and intended relations between actors confined to specific spaces." E: "the meaning, the shape, and the duration of its existence as well as the intensity, frequency, balance, prominence and speed of contacts, exchanges and transfers."

${ }^{13}$ Sanjay Subrahmanyam, Comércio e conflito. A presença portuguesa no Golfo de Bengala, 1500-1700 (Lisboa: Edições 70, 1994), 153.

${ }^{14}$ Sege Gruzinski, "Os mundos misturados da monarquia católica e outras connected histories", Topoi (2001): 176.
} 
criação e as iniciativas promovidas pela NEF/LIEN e ponderamos as razões que levaram a New Education Fellowship e a Ligue Internationale pour I'Éducation Nouvelle a serem percebidas como entidades distintas em algumas historiografias da educação. Na segunda e terceira parte, detemo-nos na atuação do TC e do IJJR, evidenciando seu papel de hub. Para tanto, debruçamo-nos também sobre associações/instituições que lhes são contemporâneas, insistindo sobre a circulação internacional de sujeitos educacionais, tomados a partir da historiografia da educação brasileira.

\section{NEF e LIEN: dois rótulos, uma mesma entidade}

A historiografia situa o nascimento da NEF/LIEN no Congresso de Calais, realizado em 1921, sob a liderança de três nomes: Beatrice Ensor; Adolphe Ferrière; e Elisabeth Rotten. Nos seus primórdios, a NEF/LIEN se constituía como a reunião de grupos muito heterogêneos, envolvendo tanto professores quanto pessoas interessadas na educação com os mais diferentes perfis, entre eles leigos e sujeitos vinculados à teosofia. Por um lado, suas raízes remetem à Fraternity of Education, grupo teosófico fundado por Ensor, em Londres, em 1915. Por outro, aglutinava iniciativas anteriores, como o BIEN, criado por Ferrière. Nesse sentido, qualquer definição mais precisa da organização teria por efeito divisão e não aglutinação em torno de alguns preceitos comuns, como a educação para a paz e a fundação de um novo mundo mais solidário, refratário ao terror das guerras, reação à recente saída da Europa de um conflito armado de grandes proporções. ${ }^{15}$

A imprecisão, assim, funcionava também como uma estratégia de consolidação de um movimento que, naquele momento, se percebia como de caráter social e político, não necessariamente acadêmico. Indiciária é a dupla denominação que assumiu nos circuitos anglófono e francófono. Em inglês, o termo New Education Fellowship preservava, por meio do termo fellowship, o caráter de associativismo expresso na palavra fraternity de Fraternity of Education, ao mesmo tempo que elidia as referências mais diretas à teosofia. No entanto, a tradução para o francês como Ligue Internationale pour I'Éducation Nouvelle não exibe uma correspondência semântica.

A dificuldade de tradução do nome em inglês para outros idiomas bem como os significados intrínsecos foram alvos de discussões desde os primórdios da NEF/LIEN e emergiram com frequência nas pautas da organização. Em 1932, uma das discussões sobre a mudança de nome, documentada com maiores detalhes, aparece em relatório encaminhado ao Comitê Consultivo. A proposta de reorganização da NEF/LIEN sugerida

\footnotetext{
${ }^{15}$ A bibliografia sobre a NEF/LIEN é ampla e transita por diferentes temas. Sobre sua criação e primeiras décadas, conferir, por exemplo, William Boyd e Wyatt Rawson, The Story of the New Education (London: Heinemann, 1965); M. D. Lawson, "The New Education Fellowship: the formative years", Journal of Educational Administration and History 13, no. 2 (1981); Celia M. Jenkins, "The professional middle class and the social origins of progressivism: a case study of the New Education Fellowship, 1920-1950" (Tese de doutorado, University of London, 1989); Sue Middleton, “New Zealand Theosophists in 'New Education' networks, 1880s1938", History of Education Review 46, no. 1 (2017); Sue Middleton, "Clare Soper's hat: New Education Fellowship correspondence between Bloomsbury and New Zealand, 1938-1946", History of Education 42, no. 1 (2013): 92-114.
} 
no documento emergiu frente às tentativas de estabelecer parceria com a PEA. 0 primeiro ponto diz respeito justamente sobre o nome da organização, afirmando logo na primeira frase que essa era uma questão que já vinha sendo discutida há muito tempo. Foram apresentados três argumentos a favor de manter o nome:

a) É bem conhecido no mundo todo.

b) 0 termo 'New Education' indica a função de nossa organização enquanto um corpo pioneiro, cujo propósito é adaptar a educação continuamente às necessidades em mudança da sociedade. Uma Educação Nova está sempre sendo necessária.

c) 'Fellowship'. Esta palavra descreve não apenas um dos princípios da Fellowship mas também seu método de trabalho. A NEF é formada por indivíduos que desejam se reunir em associação para discutir problemas em comum e tentar solucioná-los. ${ }^{16}$

Na sequência, foram apresentados quatro argumentos contra a manutenção do nome.

a) 0 termo 'New Education' frequentemente sugere que é algo inteiramente diferente e remoto do antigo. Na verdade, a NEF considera o seu movimento como procedente diretamente dos grandes movimentos educacionais do passado.

b) Talvez fosse mais fácil para a Progressive Education Association aderir ao movimento internacional se a NEF mudasse 0 seu nome.

c) A palavra 'Fellowship' nos EUA é frequentemente empregada para denotar o que chamamos 'scholarship' na Europa.

d) Também tem sido considerado extremamente difícil traduzir a palavra 'Fellowship' para o francês ou alemão. ${ }^{17}$

Um dos desdobramentos da dificuldade de tradução foi autorizar que seções e grupos com outros idiomas adotassem variações do nome em inglês, visto que em algumas

\footnotetext{
${ }^{16}$ Document 17. To members of the Consultative Committee of the New Education Fellowship. Proposal for the re-organization of the New Education Fellowship, março, 1932. (World Education Fellowship papers, Institute of Education, London, WEF/A//34). No original: "(a) It is now well-known all over the world. (b) The term "New Education" indicates the function of our organization as a pioneer body, the purpose of which is to adapt education continuously to the changing needs of society. A New Education is always being needed. (c) 'Fellowship'. This word describes not only one of the essential principles of the Fellowship but also its method of work. The NEF is made up of individuals who desire to come together in fellowship to discuss common problems and attempt a solution of them."

${ }^{17}$ Document 17. To members of the Consultative Committee of the New Education Fellowship. Proposal for the re-organization of the New Education Fellowship, março, 1932. (WEF///A/34). No original: "(a) The term 'New Education' often suggests that it is something entirely different and remote from the old. Actually the NEF regards its movement as proceeding directly from the great educational movements of the past. (b) It would be easier perhaps for the Progressive Education Association to come into the world movement if the NEF changed its name. (c) The word 'Fellowship' in USA is often thought to denote what we term 'scholarship' in Europe. (d) It has also been found extremely difficult to translate the word 'Fellowship' into French or German".
} 
línguas "era impossível assegurar uma tradução satisfatória da palavra 'Fellowship"”." ${ }^{18}$ 0 tema da mudança do nome aparece em outros documentos, mas não com o mesmo detalhamento. Em 1936, por exemplo, durante encontro do Comitê, Fred Clarke relatou que em conversas com membros da África do Sul havia sido apontado que o termo new em New Education Fellowship era um elemento complicador para muitas pessoas. Frente a isso, ele sugeriu mudar para International Education Fellowship. Foi deliberado que a questão seria encaminhada para votação pelo Comitê Executivo e pelo Conselho Internacional. Apesar de não termos localizado detalhes da discussão, podemos concluir que a proposta foi recusada, visto que 0 nome foi mantido. ${ }^{19}$

Fosse pela dificuldade de tradução do termo fellowship ou pelos significados atribuídos ao termo New Education, 0 assunto ressurgia de tempos em tempos e nunca foi superado, uma vez que em 1966 a organização finalmente adotou um novo nome, World Education Fellowship, sob o qual é conhecida nos dias atuais. ${ }^{20}$ Note-se que a mudança recaiu na elisão de new e sua substituição por world, explicitando a dimensão internacional da organização.

A escolha por LIEN como a versão francesa do nome em inglês, além de ser um desdobramento da dificuldade de encontrar um termo correspondente a fellowship, também denota uma inflexão política, manifesta tanto no objetivo de tornar-se um movimento de abrangência internacional, quanto no propósito de afirmar-se como uma frente, uma liga. Muito provavelmente inspirava-se na criação recente, em 1919 em Versailles, da Liga das Nações (League of Nations ou Société des Nations), uma organização também de espectro internacional, surgida com o mesmo propósito de assegurar a paz mundial. A mudança, em novembro de 1920, da sede da Liga das Nações para Genebra, onde estava situado 0 Instituto Jean-Jacques Rousseau, abrigo de Adolphe Ferrière, e a semelhança de finalidades podem ter impulsionado a adoção do termo "Ligue" na versão em francês.

No documento de 1932, virgula que discute a reorganização da NEF, um dos pontos é a mudança do quartel-general, que então estava sediado em Londres, e uma das propostas era que em 1933 ele fosse removido para Genebra. Entre as vantagens foram apontados o fato de Genebra ser considerada um centro internacional, o que a deixaria mais próxima de movimentos internacionais e "em particular com a Liga das Nações", e que essa localização seria melhor aceita por outros países do que manter o quartelgeneral na Inglaterra. Entre os pontos negativos, o documento apontava o fato de outras organizações com objetivos semelhantes estarem sediadas em Genebra, como o BIE e a própria Liga das Nações. ${ }^{21}$

\footnotetext{
${ }^{18}$ At a meeting of the members of the Internacional Council of the New Education Fellowship, 5 agosto, 1932, Nice. (WEF/A/I/34).

${ }^{19}$ Document 33. A meeting of the members of the Committee at Headquarters was held on $3^{\text {rd }}$ dec. 1936, Dezembro, 1936. (WEF/A/I/34).

${ }^{20}$ A World Education Fellowship mantém a seguinte página na internet: http://wef-international.org/ Acessado em 31 ago. 2020.

${ }^{21}$ Document 17. To members of the Consultative Committee of the New Education Fellowship. Proposal for the re-organization of the New Education Fellowship, março, 1932. (WEF/A/I/34).
} 
A falta de um maior delineamento de sua filosofia, utilizado talvez como dispositivo agregador de educadores e leigos interessados nos novos rumos da educação, bem como a falta de correspondência direta na tradução do nome, contribuiu para a imprecisão dos contornos da fórmula, de tal sorte que, ainda nos dias atuais, algumas historiografias nacionais da educação não relacionam NEF e LIEN, e a aderência a uma ou outra denominação implica na identidade com um repertório pedagógico proveniente de determinados autores ou associado a certas instituições. 0 mesmo embaralhamento ocorre com o Instituto Jean-Jacques Rousseau, o Bureau International des Écoles Nouvelles (BIEN) e o Bureau International d'Éducation (BIE). A isto voltaremos mais adiante.

Interessa aqui, entretanto, destacar que a propagação da NEF/LIEN inegavelmente alcançou a esfera acadêmica, em particular na década de 1930, quando os Departamentos de Educação despontaram no cenário internacional de modo mais contundente. A sucessão de Congressos organizados pela NEF/LIEN, tanto as conferências internacionais, quanto as regionais; a criação de seções e grupos em diferentes países e o número de revistas pedagógicas a ela associadas dão a dimensão do espraiamento da rede e do sucesso do empreendimento na construção de uma agenda comum na arena educacional.

No entre guerras, ao todo foram realizados sete congressos internacionais. 0 primeiro, e também no qual se deu a criação formal da NEF/LIEN, ocorreu em Calais, França, em 1921 (150 participantes). A ele se seguiram os congressos de Montreux, Suíça, em 1923 (300 participantes), Heidelberg, Alemanha, em 1925 (450 participantes), Locarno, Suíça, em 1927 (1200 participantes), Elsinore, Dinamarca, em 1929 (2000 participantes), Nice, França, em 1932 (1800 participantes), e Cheltenham, Inglaterra, em 1936 (1400 participantes). Para Kevin Brehony, esses congressos tiveram papel relevante na constituição do campo das ciências da educação, marcado pelo processo de internacionalização. ${ }^{22}$ Com a eclosão da Segunda Guerra em 1939, os planos do oitavo congresso internacional tiveram que ser revistos, e o evento apenas ocorreu em 1941, em Michigan, Estados Unidos, o primeiro a acontecer fora da Europa. ${ }^{23}$

Dentre as conferências regionais da NEF, cabe destacar as realizadas na África do Sul (1934), Nova Zelândia (1937) e Austrália (1937), que contaram com ampla participação e receberam delegados de vários países, alguns de projeção internacional. A conferência na África do Sul, por exemplo, contou com a participação de John Dewey, Pierre Bovet, Harold Rugg, Helen Parkhust, enquanto que na Nova Zelândia e Austrália, estiveram Susan Isaacs, novamente Rugg, Isaac Kandel, entre tantos outros nomes conhecidos.

Além dos congressos, a criação de seções afiliadas em outros países e a vinculação de revistas pedagógicas também desempenharam importante papel na constituição de

\footnotetext{
${ }^{22}$ Rafaela Silva Rabelo, "The New Education Fellowship, the Progressive Education Association, and the US Department of State: South America as part of a complex entanglement", Paedagogica Historica 57, no. 1-2 (2021): 183-199. DOI: https://doi.org/10.1080/00309230.2021.1872660.

${ }^{23}$ Brehony, "A new education for a new era".
} 
redes internacionais, como mencionado anteriormente. Apenas para exemplificar, em



A princípio, a NEF/LIEN contava com uma revista oficial, publicada em inglês. Intitulada inicialmente Education for the New Era; a revista antecede a criação da organização, tendo sido lançada em 1920. Em 1921, o título foi encurtado para The New Era. Logo após a criação da NEF/LIEN, a revista foi cedida e passou a figurar como publicação da recémcriada organização. No início de 1922, passaram a circular duas novas revistas associadas, a Pour l'Ere Nouvelle, editada por Adolphe Ferrière, e Das Werdende Zeitalter, por Elizabeth Rotten, mas não eram simples traduções da TNE, como esclarece Ensor no editorial em que divulga a criação das revistas. Apesar de alguns artigos em comum, cada revista tinha autonomia na sua organização e escolha dos conteúdos publicados. Desta forma, a NEF/ LIEN passou a contar com revistas em três idiomas (inglês, francês e alemão) que faziam circular internacionalmente as informações e discussões promovidas pela organização. ${ }^{25}$

Ao longo dos anos, a NEF/LIEN passou a incorporar como afiliadas revistas de outros países, geralmente vinculadas às seções criadas ou elas próprias catalisadoras da criação de seções. Em 1926, a The New Era apresentava na lista de publicações quatro novas revistas afiliadas, na Bulgária, Hungria, Itália e Espanha. Em 1928, foi incorporada uma revista na Suécia, e afiliadas provisoriamente revistas na Argentina, Bélgica, Chile, Tchecoslováquia, Holanda e Portugal. ${ }^{26}$ Essa dinâmica de incorporação de novas revistas teve sequência nos anos seguintes e, por vezes, a criação de seções e grupos se davam a partir de revistas já existentes. ${ }^{27}$

Como um hub, a NEF/LIEN congregava atores com assento em diversas instituições que, por sua vez, também abraçaram investimentos internacionais. Tomar o Teachers College da Universidade de Columbia, em Nova Iorque, e o Instituto Jean-Jacques Rousseau, da Universidade de Genebra, como outros hubs permite reorientar as digressões, ampliando e matizando as análises. 0 propósito aqui não é demonstrar um direciona-

\footnotetext{
${ }^{24}$ Vidal, and Rabelo, "A criação de Institutos de Educação no Brasil".

${ }^{25}$ Vidal, and Rabelo, "A criação de institutos de educação"; Sjaak Braster e María del Mar del Pozo Andrés, "La escuela nueva en imágenes: fotografía y propaganda en The New Era (1920-1939)", Historia y Memoria de la Educación 8, (2018): 97-145; Rafaela Silva Rabelo, "0 ensino de matemática em um número especial da revista The New Era, 1934”, Bolema 33, no. 65 (2019): 1109-1132. Béatrice Haenggeli-Jenni. L'Éducation nouvelle entre science et militance: débats et combats à travers la revue Pour l'Ėre Nouvelle (1920-1940). Bern: Peter Lang, 2017.

${ }^{26}$ As revistas afiliadas em 1926 e respectivos editores foram: Bulgária (Svobodno Vaspitanie, D. Katzaroff), Hungria (A Jovo Utjain, Marthe Nemes), Itália (La Nuova Era, Arcara Gaetano). The New Era 7, no. 26 (1926). Em 1927, muda a revista italiana (L'Educazione Nazionale, Lombardo-Radice), e é incorporada uma revista da Espanha (Revista de Pedagogia, Lorenzo Luzuriaga, já iniciada em 1923). The New Era 8, no. 30 (1927). Em 1928 é incorporada uma revista sueca (Pedagogiska Spörsmal, Ester Edelstam e M. Montelius) e seis revistas são afiliadas provisoriamente, são elas: Argentina (Nueva Era, J. Rezzano), Bélgica (Het Schoolblad de Aktieve School, M. E. Vincent), Chile (La Nueva Era, Armando Hamel), Tchecoslováquia (Nové Skoly, 0. Chlup), Holanda (Tidjschrift Voor Ervaringsopvoedkunde, H. G. Hamaker e M. J. Stamperius) e Portugal (Educação Social, M. AlvaroV. Lemos). The New Era 9, no. 33 (1928).

${ }^{27}$ Algumas revistas tiveram um período de vida curto, como é o caso da Das Werdende Zeitalter, que foi encerrada em 1932. Outras eram publicadas de forma irregular, e tiveram períodos de interrupção.
} 
mento único das ações em prol da Educação Nova, mas, em consonância com 0 diagnóstico emprestado de Hameline, evidenciar que a fórmula, se servia como dispositivo agregador, não tinha potencial de limitar, ou mesmo coordenar, os esforços, dando margem a muitas interpretações e realizações.

0 método de projetos é um bom exemplo destas porosidades. Proposta que ganhou corpo e se popularizou a partir dos EUA, mas cujas origens remetem à Europa, o método de projetos recebeu diferentes significados durante seu processo de difusão por diversos países. Maria del Pozo analisa especificamente a recepção na Espanha, as diferentes formas que assumiu, e as razões para seu sucesso nos anos 1930, quando já havia sido abandonado nos EUA. ${ }^{28}$

Justamente por desempenhar o papel de um hub, a NEF/LIEN se conectava não apenas a indivíduos, mas também a organizações de naturezas diversas em vários países, algumas das quais também com várias conexões internacionais, como o veremos a seguir.

\section{TC e PEA: hubs de ideias e experiências da Educação Nova nos EUA}

A origem do Teachers College remete a 1887, quando a instituição foi fundada por Grace Hoadley Dodge, Nicholas Murray Butler e James Earl Russel, sendo incorporada pela Columbia University em 1898. 0 grupo de professores convidado a compor o quadro docente do TC é indicativos da pretensão que a instituição tinha em se consolidar como referência nos estudos em educação. De fato, essa primeira geração de professores do TC, pioneiros em diferentes frentes, construiu uma tradição e legou uma herança que alçou a instituição a uma das referências mais importantes no campo educacional, não apenas nos EUA, mas internacionalmente. Dessa geração de pioneiros, vale destacar Edward Lee Thorndike, contratado em 1899 pelo reitor James Russel, a partir da indicação de William James e James McKeen Cattel. Enquanto Thorndike assumiu o papel de liderança no campo da psicologia educacional - campo do qual é considerado um dos precursores -, John Dewey ocupou o lugar de pioneiro já amplamente conhecido na filosofia educacional. Dewey era professor do Departamento de Filosofia da Columbia University, cargo que ocupou em 1904 após deixar a University of Chicago. Apesar de não estar vinculado diretamente ao TC, ele ministrava conferências e tinha conexões com professores da ala progressista, muitos dos quais seus discípulos, como William $\mathrm{H}$. Kilpatrick, além de integrar o Departamento de Pesquisa Educacional. ${ }^{29}$ Entre os nomes de prestígio, ou que alcançaram reconhecimento após sua inserção no TC, estão Paul Monroe, Isaac Kandel, Harold Rugg, David Eugene Smith, Patty Smith Hill, Arthur Gates, George Counts, apenas para citar alguns.

\footnotetext{
${ }^{28}$ María del Mar del Pozo Andrés, "The transnational and national dimensions of pedagogical ideas: the case of the project method, 1918-1939", Paedagogica Historica 45, nos. 4-5 (2009): 561-584; María del Mar del Pozo Andrés, "0 Método de Projetos na Espanha: recepção e apropriação (1918-1936)", en Movimento Internacional da Educação Nova, ed. Diana Gonçalves Vidal e Rafaela Silva Rabelo (Belo Horizonte: Fino Traço, 2020), 189-208.

${ }^{29}$ Lawrence Cremin et al., A history of Teachers College Columbia University (Nova lorque: Columbia University Press, 1954).
} 
Nas primeiras décadas do século XX, o TC ganhou projeção internacional, resultado tanto do seu pioneirismo quanto pelo estímulo à presença de estudantes estrangeiros, que aumentou significativamente a partir dos anos 1920. Em 1923, por exemplo, havia 265 estudantes de 42 países e entre 1926 e 1927, o número de estudantes estrangeiros chegou a 457. Um dos desdobramentos foi a criação, em 1923, do International Institute, graças a uma doação do General Education Board, fundado anteriormente por John D. Rockefeller. 0 International Institute desempenhou importante papel entre os anos 1920 e 1930 no processo de internacionalização do TC por meio de missões de estudos em outros países, intercâmbio de estudantes e publicações, entre elas o Educational Yearbook. A direção do Instituto coube a Paul Monroe. Entre os professores associados estavam Isaac Kandel, Lester Wilson e Stephen Duggan.

0 International Institute era responsável por coordenar uma série de atividades voltadas para os alunos estrangeiros, tais como a promoção de viagens de estudo a diferentes escolas dos EUA. Entre as produções do Instituto estavam a International Educational Library, que era "uma das melhores coleções dessa natureza no mundo", ${ }^{30}$ e a publicação do Educational Yearbook. Editado por Isaac Kandel, o Yearbook tinha como foco a educação em vários países e continuou a ser publicado mesmo após o encerramento do International Institute, em 1938, sendo extinto em 1944 após publicar 21 números. ${ }^{31}$

Além do International Institute, o TC contava também com outros institutos relevantes, tais como o Institute of Educational Research e o Institute of Child Welfare Research. 0 primeiro foi criado em 1921 e se organizava administrativamente em torno de três divisões: Divisão de Psicologia Educacional, dirigida por Edward L. Thorndike; Divisão de Experimentação Escolar, dirigida por Otis W. Caldwell; e Divisão de Estudos de Campo, sob a gestão de George D. Strayer. Já o Institute of Child Welfare Research foi criado em 1924 a partir de uma doação do Laura Spelman Rockefeller Fund. ${ }^{32}$

0 TC foi um importante modelo para formação de professores ao redor do mundo, sendo referência para a criação de instituições semelhantes em outros países, como 0 Institute of Education da University College London ${ }^{33}$ e o Edinburgh (Teacher) Training Centre (Moray House) em Edimburgo, Escócia, nos anos 1920 e 1930,34 ou os Institutos de Educação no Brasil nos anos $1930 .{ }^{35}$ Percorrendo as listas de alunos estrangeiros que

\footnotetext{
${ }^{30}$ Cremin et al., A history of Teachers College, 74. No original: "one of the best collections of its kind in the world".

${ }^{31}$ Luis Grosso Correia, "The right kind of education for the right individual: comparative education studies according to the Educational Yearbook of the Teachers College (1924-1944)", History of Education 40, no. 5 (2011): 577-598.

${ }^{32}$ Cremin et al., A history of Teachers College.

${ }^{33}$ Richard Aldrich, "The training of teachers and educational studies: the London Day Training College, 1902-1932", Paedagogica Historica, 40, no. 5-6 (2004): 617-631; Gary McCullock, "Fred Clarke and the internationalisation of studies and research in education", Paedagogica historica 50, no. 1-2 (2014): 123-137. ${ }^{34}$ Martin Lawn, "Um conhecimento complexo: 0 historiador da educação e as circulações transfronteiriças", Revista Brasileira de História da Educação 14, no. 1 (2014): 127-144.

${ }^{35}$ Vidal, and Rabelo, "A criação de Institutos de Educação".
} 
frequentaram o TC é possível perceber como esse modelo de formação de professores alcançou o mundo. Entre os anos 1920 e 1930, por exemplo, cerca de 130 alunos ingleses frequentaram a instituição, ${ }^{36}$ enquanto que no mesmo período 24 brasileiros concluíram seus estudos. ${ }^{37}$ Mesmo após a extinção do International Institute, o TC continuou a ser uma importante referência internacional e destino de estudantes estrangeiros.

As tramas que unem o TC e a NEF/LIEN envolvem diferentes elementos em um jogo de composições e recomposições que a trajetória dos sujeitos na constituição do campo educacional suscitou, entre eles a Progressive Education Association. Segundo Graham, ${ }^{38}$ em sua origem, a PEA era uma organização composta principalmente por professores e administradores ligados a escolas elementares e secundárias, particulares em sua maioria. Entre o final dos anos 1920 e início dos 1930, havia sido praticamente tomada por educadores profissionais, com presença marcante de professores do Teachers College, o que paulatinamente foi mudando as pautas da associação e sua dinâmica de funcionamento.

Vários membros da PEA eram nomes conhecidos internacionalmente. Carleton Washburne, que foi superintendente das escolas de Winnetka, Illinois, entre 1919 e 1943, exemplifica o perfil dos membros da primeira fase, que não tinham vinculação universitária. Washburne foi um membro atuante na PEA, desde os anos 1920 até a sua extinção. Também foi membro da NEF, participando de congressos internacionais e publicando nas revistas associadas com frequência. Foi presidente em ambas associações: na PEA, entre 1939 e 1943, e na NEF/LIEN, entre 1949 e $1956 .{ }^{39}$

Entre os nomes vinculados a universidades e de projeção internacional é possível citar William Kilpatrick e Harold Rugg, ambos professores do TC. Assim como Washburne, também participaram de congressos da NEF/LIEN e publicaram nas revistas associadas. Harold Rugg, em especial, foi um dos defensores de uma maior aproximação da PEA com a NEF/LIEN, o que, em 1932, resultou na criação da primeira seção da NEF/LIEN nos EUA. Rugg foi o representante oficial de ligação entre as duas organizações até 1944, quando foi destituído do cargo devido a atritos dentro da PEA.

Outro membro da PEA, também vinculado à Columbia University, foi o renomado filósofo norte-americano John Dewey. Dewey assumiu como presidente honorário da

\footnotetext{
${ }^{36}$ Levantamento realizado a partir dos inventários de alunos estrangeiros registrados em cada semestre letivo ou nos cursos de férias. Esses registros incluem tanto alunos que permaneceram por um curto período, por exemplo, frequentando as sessões de inverno ou verão, quanto alunos que cursaram alguma pós-graduação e obtiveram um título.

${ }^{37}$ Students from Latin American Countries Registered in Teachers College, Columbia University, 1920-1940. Pocketknowledge, Gottesman Libraries, Teachers College, Columbia University.

${ }^{38}$ Patricia Albjerg Graham, Progressive Education: from arcady to academe. A history of the Progressive Education Association, 1919-1955 (New York: Teachers College Press, 1967).

${ }^{39}$ Patricia Albjerg Graham, "Carleton Wolsey Washburne: a biographical essay", Teachers College Record 72 , no. 6 (1971).
} 
PEA em 1926, título que manteve até seu falecimento em $1952 .{ }^{40}$ Há registros de sua participação em pelo menos um congresso da NEF/LIEN, o congresso regional realizado na África do Sul, nas cidades de Cape Town e Johannesburg, em 1934. A presença de vários nomes de relevo do TC na PEA não implica que a PEA, ou a educação progressiva de uma forma geral, fosse consenso no TC. De fato, mesmo dentro da PEA conviviam diferentes percepções do que seria - ou deveria ser - a educação progressiva e a filosofia da associação.

Isaac Kandel ilustra bem essas disputas no TC. Tido como um educador mais tradicional e alinhado com as discussões curriculares, era um ferrenho crítico da educação progressiva, todavia 0 vemos transitando pela NEF/LIEN. Em 1937, por exemplo, participou da conferência da NEF/LIEN na Austrália, além de integrar o comitê inicial que discutiu a criação de uma seção da NEF/LIEN nos EUA. ${ }^{41}$ Podemos interpretar 0 seu trânsito pela NEF/LIEN a partir dos elementos que os uniam, ou seja, a internacionalização dos estudos e pesquisas em educação. A posição que ocupava no International Institute 0 impulsionava a estabelecer interlocução com organizações diversas, independentemente das divergências filosóficas e pragmáticas na arena educacional.

A PEA e a NEF/LIEN tiveram uma relação próxima desde o início, impulsionada talvez pela data próxima de criação (1919 e 1921, respectivamente), mas principalmente pelos interesses em comum em promover novos métodos de educação e em considerar a criança como o centro do processo educativo. Portanto, quando a NEF/LIEN foi criada, e passou a organizar regularmente congressos internacionais, a aproximação foi um desdobramento natural. Considerando as semelhanças entre as organizações, a NEF/LIEN buscava estabelecer uma parceria com a PEA, e não apenas a criação de uma seção. Tentando atingir esse objetivo, chegou a ser cogitada a mudança do nome da NEF/LIEN, como comentado anteriormente, e mesmo a mudança do quartel-general. ${ }^{42}$

Todavia, a relação também foi permeada de atritos e mesmo disputas por protagonismo, o que resultou na criação da seção da NEF/LIEN nos EUA apenas em 1932, após longas negociações. Um dos fatores que impediu a criação da seção antes, segundo Graham, foi a animosidade que Stanwood Cobb, presidente da PEA entre 1927 e 1929, tinha em relação a Ensor. ${ }^{43}$

Com a criação da seção em 1932, ao longo dos anos 1930 a PEA ganhou mais espaço na NEF/LIEN, e começou a atuar como liaison na América Latina, papel esse que

\footnotetext{
${ }^{40}$ Graham, Progressive Education. Dewey foi convidado para o cargo após o falecimento Charles William Eliot, 0 primeiro presidente honorário da PEA e ex-presidente de Harvard. Graham, Progressive Education.

${ }^{41}$, Rafaela Silva Rabelo, "Isaac Kandel e a constituição de redes entre Brasil e Estados Unidos", Revista de Ciências da Educação 21, no. 43 (2019): 67-96.

${ }^{42}$ Ver, por exemplo, At a meeting of the members of the Consultative Committee of the New Education Fellowship, August 2, 1932; At a meeting of the member of the Executive Board of the New Education Fellowship and representatives of the Progressive Education Association and of the American Committee on International Education, August 7, 1932 (WEF/A///34).

${ }^{43}$ Graham, Progressive Educatio, 42.
} 
até então era desempenhado por Ferrière. ${ }^{44}$ Essas mudanças parecem ter ganho maior proporção após o congresso da NEF/LIEN em Cheltenham, Inglaterra, em 1936, em que os EUA foram cogitados como país anfitrião do congresso internacional seguinte. As crescentes tensões, que culminaram na Segunda Guerra em 1939, podem ter sido decisivas para a confirmação dos EUA como país a sediar a oitava conferência, que teve que ser adiada para 1941.45

As semelhanças entre PEA e a NEF/LIEN ultrapassavam os interesses em comum nutridos pelas duas organizações, e incidiram também nos problemas enfrentados para se manterem. As tentativas da PEA em atrair mais membros bem como as diferentes vertentes que ela abrigava levavam a uma falta de definição de sua identidade. As dificuldades financeiras também foram uma constante, tornando cada vez mais difícil conseguir fontes de financiamento, principalmente no pós-guerra. Com as críticas crescentes à educação progressiva, que se intensificaram na segunda metade dos anos 1930, sendo associada inclusive ao comunismo, principalmente com a eclosão da Segunda Guerra e no período que se seguiu, o termo "progressivo" assumiu um tom pejorativo. Não por acaso, em 1944, a associação alterou seu nome para American Education Fellowship, apenas para retomar 0 antigo nome em 1953, e ser extinta pouco depois, em 1955. A revista oficial da PEA, Progressive Education, continuou a ser publicada sob os auspícios da John Dewey Society, até 1957, quando finalmente foi encerrada. ${ }^{46}$

Como hubs, o TC e o International Institute estabeleceram conexões com vários educadores brasileiros, dentre outros, Isaías Alves, Noemy Marques da Silveira (também conhecida como Noemy Rudolfer) e um grupo de professoras de Minas Gerais. ${ }^{47} 0$ caso mais célebre refere-se a Anísio Teixeira. 0 educador baiano foi aos Estados Unidos da América pela primeira vez em 1927. No ano seguinte, retornou, matriculando-se no TC, onde conquistou o título de Master of Arts em 1929. A partir do contato com as ideias de John Dewey, Teixeira assumiu a defesa da Educação Progressiva, diferindo dos educadores brasileiros que preferiam aderir ao termo Educação Nova. Traduziu vários textos do filósofo estadunidense ao português e se constituiu em uma das principais referências sobre educação democrática no país. A experiência nos EUA facultou-lhe, ainda, encontrar William Killpatrick e beneficiou os planos de criação do Instituto de Educação do

\footnotetext{
${ }^{44} \mathrm{~A}$ respeito do papel de Ferrière nas conexões com a América Latina, conferir Joseph Coquoz, "Le Home 'Chez Nous' comme modèle d'attention à l'enfance", Educació i Història: Revista d'Història de l'Educació, n. 20 (2012); Joan Soler Mata, "Entre Europa i América Llatina: Adolphe Ferrière i l'Escola Nova a Barcelona", Temps d'Educació, n. 35 (2008).

${ }^{45}$ Rabelo, "The New Education Fellowship".

${ }^{46}$ Graham, Progressive Education.

${ }^{47}$ Conferir, por exemplo, Rabelo, "Isaac Kandel e a constituição de redes"; Roberta Maira de Melo Araújo, "Benedicta Valladares Ribeiro (1905-1989): formação e atuação" (Tese de Doutorado, Universidade de São Paulo, 2010); Nelma Marçal Fonseca, "Alda Lodi, entre Belo Horizonte e Nova lorque: um estudo sobre formação e atuação docentes 1912-1932" (Dissertação de Mestrado, Universidade Federal de Minas Gerais, 2010), Ana Cristina Matos Rocha, "Experiências norte-americanas e projetos de educação no Distrito Federal e em São Paulo (1927-1935): Anísio Teixeira, Noemi Silveira, Isaías Alves e Lourenço Filho" (Tese de Doutorado, Fundação Oswaldo Cruz, 2016).
} 
Distrito Federal (Rio de Janeiro) em 1932, com o recurso aos cursos de matéria, perspectiva adotada em consonância ao praticado no TC. ${ }^{48}$ Como destaca Carlos Roberto Cury, ${ }^{49}$ entretanto, antes da viagem aos EUA, em 1925, Anísio estivera na Europa, permanecendo quatro meses em Paris, quando frequentou classes na Sorbonne e estudou a reforma do sistema educacional francês, sendo particularmente influenciado pela ênfase da presença do Estado na organização da escolarização gratuita, secular e pública.

Anísio Teixeira foi um dos signatários do Manifesto dos pioneiros da educação nova, lançado em 1932, considerado pela historiografia brasileira como documento fundador de um grupo de educadores, que se tornou conhecido por escolanovistas no Brasil. Não é 0 caso de retraçar, aqui, sua biografia, objeto de vários estudos, ${ }^{50}$ que detalham a passagem por cargos da administração pública educacional, a decisiva atuação em prol da educação pública estatal e 0 trabalho como tradutor. Mas insistir na circulação deste sujeito que, em 1946, viria a ser convidado por Julian Huxley, primeiro diretor geral da UNESCO, para trabalhar como Consultor em Educação Superior. 0 contato entre os dois surgira da tradução feita por Teixeira, em 1938, do livro The Science of life, do qual era coautor junto a H.G. Wells. ${ }^{51}$ A inserção na UNESCO foi breve, durou apenas um ano, mas marcou o retorno de Anísio à vida pública em período que coincidia com o final da ditadura de Vargas no Brasil e do conflito armado na Europa, deu substância a um novo projeto que implementou na cidade de Salvador, Bahia, e que ficou internacionalmente conhecido: a Escola Parque Carneiro Ribeiro. Samira Chahin demonstra como a estadia no TC e atividade na UNESCO se entrelaçam na elaboração de um plano de ocupação da cidade pela escola que seria testado inicialmente na Bahia, em 1950, e depois estendido na construção da nova capital brasileira em Brasília, em 1960. ${ }^{52}$

Como um mediador cultural, Teixeira circulou entre mundos, apropriou-se de e retramou saberes e práticas, constituiu redes e impactou o cenário nacional e internacional da educação. 0 circuito, no entanto, pode ser invertido e considerado a partir do TC e da PEA em direção ao Brasil. Para abordá-Io, convidamos um outro ator, Carleton Wolsey Washburne que, em sua viagem ao Brasil, em 1942, iria contribuir para o estabelecimento da seção brasileira da NEF/LIEN, associada ao Instituto Nacional de Estudos Pedagógicos (INEP) e a outra figura maior da Educação Nova no país, Manuel Bergstrom Lourenço Filho, também signatário do Manifesto, em 1932.

\footnotetext{
${ }^{48}$ Diana Vidal. 0 exercício disciplinado do olhar. livros, leituras e práticas de formação docente no Instituto de Educação do Distrito Federal (1932-1937) (Bragança Paulista: Editora da Universidade São Francisco, 2001).

${ }^{49}$ Carlos Roberto Cury."Anisio Teixeira (1900-1971)". Prospects: the quarterly review of comparative education XXX, no. 4 (2000): 509-20.

${ }^{50}$ Para restringirmo-nos a apenas uma indicação, escolhemos o doutorado de Clarice Nunes, Anísio Teixeira: a poesia da ação (Bragança Paulista: EDUSF, 2000), referência inescapável quando se aborda a questão.

${ }^{51}$ Silvia Assam da Fonseca, "A coleção Bibliotheca do espírito moderno: um projeto para alimentar espíritos da Cia. Editora Nacional (1938-1977)", (Tese de doutorado, PUC-SP, 2010).

${ }^{52}$ Samira Bueno Chahin, "Cidade nova, escolas novas? Anísio Teixeira, arquitetura e educação em Brasília" (Tese de Doutorado, Universidade de São Paulo, 2018).
} 
Entre abril e setembro de 1942, Carleton Washburne excursionou pela América do Sul, passando por Colômbia, Equador, Chile, Paraguai e Brasil. Seu itinerário incluiu visitas a instituições de ensino, encontros com autoridades políticas e educadores renomados em seus países, além de palestras sobre a Educação Nova. A viagem foi comissionada pela Division of Cultural Relations do Departamento de Estado dos EUA e consistia em missão de estudo sobre os problemas da educação nos países sul-americanos. Além disso, criou seções da NEF/LIEN nos cinco países visitados. Colômbia e Equador, por exemplo, já haviam abrigado grupos ou seções desde os anos 1930, mas para o Brasil essa era a primeira seção criada, e se dava por intermédio de conexões com os EUA. Na época, Washburne era o presidente da PEA, que havia se tornado seção da NEF/LIEN em 1932, como mencionado anteriormente. Todavia, os vínculos de Washburne com a NEF/LIEN remetem aos anos 1920. Em seus escritos, ele esclarece que tomou conhecimento da organização durante missão de estudo pela Europa entre 1922 e 1923, e que se baseou no livro de Ferrière, L'Ecole Active, para planejar as visitas às escolas europeias. Em nova incursão pela Europa, em 1931, colheu informações para planejar a viagem a partir da NEF/LIEN e do International Institute. ${ }^{53}$

As viagens de Carleton Washburne e as redes que constituiu, a exemplo de Anísio Teixeira, evidenciam, a partir da interseção de trajetórias e das múltiplas vinculações de alguns personagens, as conexões entre diferentes instituições como TC, PEA, NEF/LIEN e IJJR.

\section{IJJR, BIE e BIEN: outras siglas que se embaralham na circulação de ideais e práticas associadas à Educação Nova}

Do outro lado do Atlântico, outra instituição com ambição internacional e pautada pelo desejo de renovação educacional espraiava sua atuação e envolvia estudantes estrangeiros. Criado em 1912 por Edouard Claparède, com o duplo propósito de fornecer uma sólida formação em psicologia e pedagogia aos futuros mestres e oferecer os meios de construção de uma nova ciência da educação por intermédio de um instituto de pesquisa, considerado como um grande laboratório, o Instituto Jean-Jacques Rousseau simbolizava em seu nome uma convicção e um programa, de acordo com Fernando Vidal. ${ }^{54}$ Esclarece: "na epígrafe de seu artigo fundador, Claparède incluiu a frase de Rousseau: 'Comecem assim por estudar seus alunos, pois muito seguramente não os conhecem'. Se a escola fracassa, é porque os educadores ignoram a infância". ${ }^{55}$

\footnotetext{
${ }^{53}$ Rabelo, "The New Education Fellowship"; Rafaela Silva Rabelo e Diana Gonçalves Vidal, "A seção brasileira da New Education Fellowship: (des)encontros e (des)conexões", en Movimento Internacional da Educação Nova, editado por Vidal e Rabelo (Belo Horizonte: Fino Traço, 2020).

${ }^{54}$ F. Vidal, idem, 85.

${ }_{55}$ Idem, ibidem. No original: [Em épigraphe de son article foundateur, Claparède met une frase de Rousseau: "Commencez donc par étudier vos élèves, car très assurément vous ne les connaissez point"... Si l'école échoue, c'est que les éducateurs ignorent l'enfance".
} 
As quatro funções, detalhadas por Claparède para serem exercidas pelo Instituto, manifestavam estes compromissos, conforme relata Rita Hofstetter. ${ }^{56}$ Eram elas:

\begin{abstract}
0 Instituto como uma escola permite educadores para orientarem-se, serem documentados, mas também colaborar na construção da ciência pedagógica e treinarem-se no método científico.
\end{abstract}

0 Instituto como um centro de pesquisa conduz investigação necessária para o desenvolvimento da ciência educacional, incluindo estudantes que também contribuem.

0 Instituto como um centro de informação coleciona estudos psicopedagógicos, tornando-os acessíveis por meio de uma revista e uma biblioteca

0 Instituto é também um centro de reforma pedagógica urgindo respeito pelos direitos da criança. ${ }^{57}$

A decisão por estabelecer o Instituto de Ciências da Educação como um instituto privado em lugar de associado a uma universidade pública deveu-se às dificuldades enfrentadas por Claparède para introduzir suas ideias pedagógicas no seio da academia por meio de "cursos, grupo de estudo sobre a psicologia da criança, seminários para professores sobre psicopedagogia, que integravam diferentes faculdades como ciências, artes, pedagogia e medicina". ${ }^{88}$ Outras duas razões são ainda apresentadas por Hofstetter ${ }^{59}$. uma maior liberdade para manter sinergia entre as disciplinas e o contexto sociocultural e político de Genebra que favorecia o mecenato por parte de famílias protestantes bem estabelecidas em apoio a iniciativas de educação e ciência. É importante ter em conta que tanto Claparède, quanto Pierre Bovet, diretor do Instituto Jean-Jacques Rousseau até 1944 , eram provenientes da aristocracia protestante suíça, ${ }^{60} 0$ que por certo favoreceu a ativação das redes de sociabilidade em suporte ao empreendimento. Daniel Hameline ${ }^{61}$ incluiu uma quarta razão: a facilidade dos docentes de engajarem mais livremente os alunos na investigação e incitá-los ao trabalho. Não é certo afirmar, no entanto, que 0 Instituto não nutrisse fortes vínculos com a Universidade, tanto pela oferta de cursos quanto pelo acolhimento de seus professores.

\footnotetext{
${ }^{56}$ Rita Hofstetter, "The construction of a New Science by means of na institute and its communication media: the institute of educational sciences in Geneva (1912-1948)", Paedagogica Historica, 40, no. 5-6 (2004): 657683.

${ }^{57}$ Hofstetter, idem, 663. No original: "- The Institute as a school allows educators to orient themselves, to be documented, but also to collaborate in the construction of the pedagogical science and to train themselves in the scientific method. - The Institute as a research centre conducts research necessary for the development of educational science, including students who also contribute. - The Institute as an information centre collects psychopedagogical studies making them accessible via a journal and a library. — The Institute is also a pedagogical reform centre urging respect for children's rights".

${ }^{58}$ Hofstetter, idem, 665. No original: courses, group psychological study of the child, teacher seminars on psychopedagogy which integrated different academic faculties such as science, arts and pedagogy, and medicine.

59 Idem, ibidem.

${ }^{60}$ F. Vidal, idem, 85

${ }^{61}$ Daniel Hameline. L'Éducation dans le miroir du temps. (Lausanne: Société coopérative des Editions des Sentiers, 2002), 253.
} 


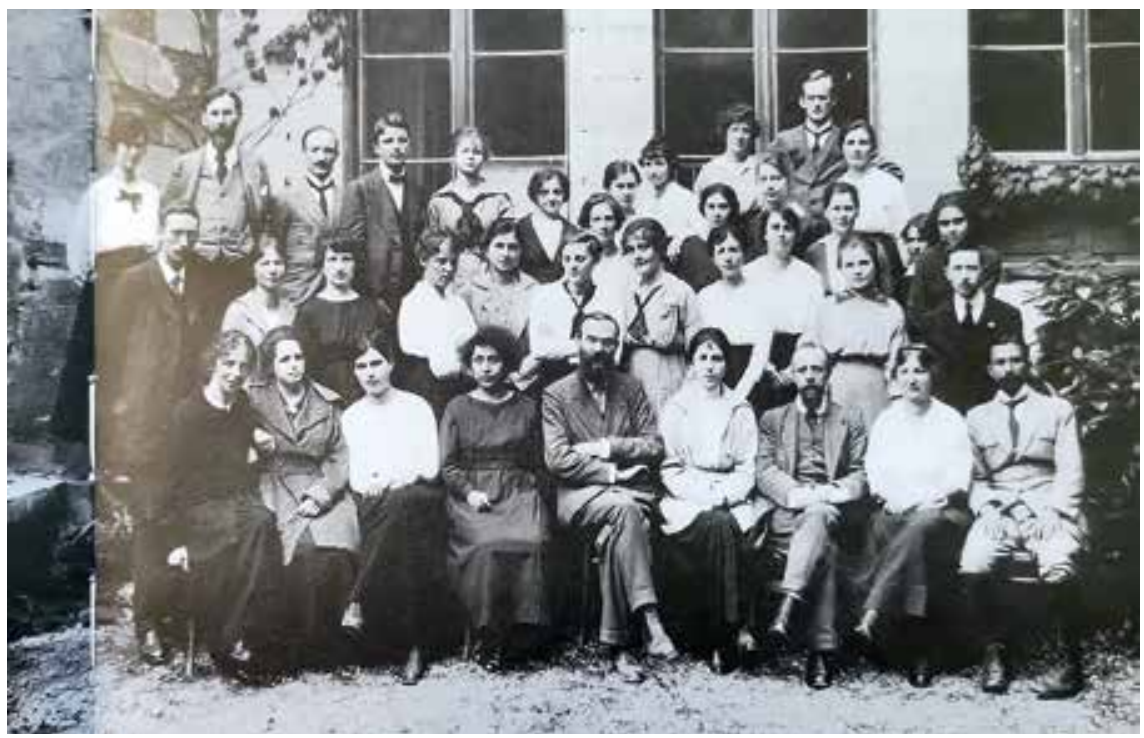

0 curso de Ciencias da Educación no Institut Jean Jacques Rousseau de Xenebra reuniu este conxunto de alumnas, alumnos e profesores. Arriba, á esquerda, Claparède, abaixo, en posición central, Bovet (Cent ans de vie, 1912-2012, p.43).

A primeira Grande Guerra freou momentaneamente a expansão internacional do IJJR, e os eventos que lhe sucederam como a chamada gripe espanhola e a greve geral de 1918, repercutiram em uma forte crise financeira, da qual o Instituto foi resgatado pelo suporte do corpo de professores da Suíça francófona, ${ }^{62}$ por meio da Société des Amis de l'Institut. Em 1925, tanto os engajamentos científicos quanto a audiência internacional permitiram ao IJJR angariar apoio financeiro da Laura Spelman Rockfeller Memorial Fund e geraram a oportunidade para a fundação do Bureau International d'Éducation (BIE). Para Hofstetter et al, ${ }^{63}$ a militância educacional colocou em risco a constituição da educação como disciplina e ameaçou fragilizar o IJJR. No embate entre interesses locais e internacionais, em 1929, a integração do IJJR à Faculdade de Letras da Universidade de Genebra significou, simultaneamente, o compromisso com a vaga que consagrava o campo educacional como um investimento universitário e 0 fim do empreendimento privado.

Nesta primeira fase do IJJR, entre 1912 e 1929, muitas foram as iniciativas levadas a cabo, como destaca Rita Hofstetter. ${ }^{64}$ Dentre elas, interessa-nos destacar apenas duas:

\footnotetext{
${ }^{62}$ Hameline, L'Éducation dans le miroir du temps, ibidem.

${ }^{63}$ Rita Hofstetter, Bernard Schneuwly, Valérie Lussi e Béatrice Haenggeli, "Genève dans le contexte international, em Rita Hofstetter \& Bernard Schneuwly (ed.), Passion, fusion, tension. New Education and Educational Sciences (Berne. Peter Lang, 2006): 107-142

${ }^{64}$ Hofstetter, "The construction of a new science", 666.
} 
a criação da Maison des Petits, em 1913-1914, que se tornou centro de peregrinação pedagógica para educadores no entreguerras, ${ }^{65}$ e do, acima mencionado, Bureau International d'Éducation, em 1925, que teve por propósito estimular a cooperação intelectual, a solidariedade internacional e a renovação educacional. $0 \mathrm{BIE}$, em intensa colaboração com o IJJR, a partir de 1926, reteve uma substantiva documentação sobre iniciativas educacionais no mundo, bem como organizou diversos eventos internacionais, como por exemplo o Congresso da NEF/LIEN de Locarno, em 1927.66

A Maison des Petits oferece um exemplo importante da hibridação de teorias e práticas pedagógicas característica do movimento da Educação Nova. Daniel Hameline ${ }^{67}$ organizou a história de seus primeiros anos a partir de dois episódios. 0 primeiro considerou montessoriano. 0 segundo derivou da atuação de Mina Audemars e Louise Lafendel, as duas diretoras da escola, e para o autor se caracterizou pelo que denominou de écletisme rausonné, negando, inclusive que pudesse ser considerado claparédie. No que concerne ao primeiro episódio, sua duração foi breve, mas está no coração da origem da Maison. Decorreu de convite efetuado por Pierre Bovet a Teresina Bontempi e Jeanne Barrère para ministrarem um curso no IJJR sobre o método Montessori. Durante um mês todas as manhãs, um grupo de uma dúzia de crianças entre 3 e 7 anos, dentre as quais estavam os filhos de Claparède e de Bovet, se reuniam para efeito de demonstração. Ao final da experiência, os educadores resolveram manter esta pequena classe, a pedido de vários pais. As crianças foram então confiadas a três alunas do IJJR, Helena Antipoff, Marguerite Eugster e Marguerite Gagnebin, que permaneceram na função até 1914.

0 segundo episódio se inaugurou em 1914 e perdurou até 1945 com a contratação de Mina Audemars e Louise Lafendel. Ambas exibiam uma formação e trajetória profissional com 0 método froebeliano, em sua interpretação genebrina. ${ }^{68} \mathrm{E}$, de acordo com Hameline, desenvolveram na Maison uma estratégia que vinham elaborando desde 1910 e que consistia em quatro imperativos: "Não hesitar em bricolar o material educativo, manter a propriedade onde ela se encontra, colocar ideias e instrumentos à prova de uma prática ao mesmo tempo engenhosa e refletida, dispor de uma concepção geral da infância que sirva de credo sem engendrar rigidez dogmática. ${ }^{69}$ Com este espirito de bricoleur, as educadoras entreteceram Froebel, Montessori e Decroly, aderindo ao método experimental, sem se subordinarem "ao prestígio de uma personalidade". ${ }^{70} \mathrm{Na}$ avaliação

\footnotetext{
${ }^{65}$ Daniel Hameline "Aux origins de la Maison des Petitis". Christiane Perregaux, Laurence Rieben et Charles Magnin (dir). Une école où les enfants veulent ce qu'ils font; La Maison des Petits hier et aujourd'hui. (Lausanne: Société coopérative des Editions des Sentiers,1996), 17-62.

${ }^{66}$ Hofstetter, "The construction of a new science", 667.

${ }^{67}$ Hameline, "Aux origins de la Maison des Petitis", 19.

${ }^{68}$ Hameline, "Aux origins de la Maison des Petitis", 25.

${ }^{69}$ Hameline, "Aux origins de la Maison des Petitis", 25-26. No original: "ne pas hésiter à bricoler le matériel éducatif, prendre son bien là où on le trouve, mettre les idées et les instruments à l'épreuve d'une pratique à la fois ingénieuse et réfléchie, disposer d'une conception globale de enfance qui serve de credo sans engendrer de raideur dogmatique".

${ }^{70}$ Hameline, "Aux origins de la Maison des Petitis", 27.
} 
de Hameline, entretanto, a falta aparente de uma doutrina firme era uma característica de todo o movimento da Educação Nova e não apenas do IJJR, como já destacamos anteriormente.

É ainda este autor que nos guia ao retraçar a história do Bureau Internacional de l'Education (BIE), evocando três datas (1923, 1925 e 1929), que no curto espaço de tempo de 6 anos anunciaram mutações no escopo da entidade. A primeira antecedeu a criação oficial, mas já estabelecia a relação entre $0 \mathrm{BIE}$, a NEF/LIEN e a Société des Nations (ou Liga das Nações). 0 II Congresso da NEF/LIEN, realizado em Montreaux, enviou a Henri Bergson, então presidente da Comissão de cooperação intelectual da Liga das Nações, uma moção recomendando "0 estabelecimento em Genebra de um Bureau internacional de educação, escritório de informações e de estudos científicos cuja necessidade se faz universalmente sentir". ${ }^{11}$

Ao final da Primeira Grande Guerra, multiplicaram-se as instituições e associações com o objetivo de promover a solidariedade dos povos, a cooperação intelectual e a educação pacifista e internacionalista. Genebra foi alçada em projeção internacional como local escolhido para a instalação de várias delas, como a Liga das Nações e o Bureau International du Travail, portanto, solo fértil para a implantação do BIE. É nesse contexto que, de acordo com Hofstetter et all, ${ }^{72}$ Adolphe Ferrière assume a posição de figura chave do IJJR na militância em prol do movimento educacional mundial pela reforma "da humanidade através da educação", por meio de principalmente três iniciativas: sua participação em Calais na criação da NEF/LIEN, em 1921; o sucesso obtido pelo livro L'école active, saído em 1922; e a oportunidade, em 1923, de proposição do que viria a ser o BIE, ligado ao Bureau International des Écoles Nouvelles (BIEN), fundado por ele em 1899 e do qual era o único responsável até então. ${ }^{73}$

A segunda data referida por Hameline, 1925, consistia na fundação do BIE, como uma entidade cosmopolita ${ }^{74}$, ligada ao IJJR, a partir da atuação conjunta de Ferrière, Claparède e Bovet, tendo Bovet como diretor e Ferrière como diretor adjunto. ${ }^{75} \mathrm{Em}$ seu Estatuto, o BIE afirmava manter a neutralidade nacional, politica, confessional e filosófica e se apresentava como órgão de documentação e de estudos, eivado de um espírito estritamente científico e objetivo. Dentre os objetivos, estava a promoção de um espírito internacional na juventude pelo trabalho conjunto das associações em favor da Liga das Nações. Escapando, portanto, ao controle dos Estados, o BIE se prestava a agir em prol dos interesses particulares, sempre preservando 0 compromisso com 0 bem comum. ${ }^{76}$ Foi durante esta fase que o BIE realizou, em 1927, o Congresso da NEF/LIEN de Locarno.

\footnotetext{
${ }^{71}$ Hameline, L'Éducation dans le miroir du temps, 196. No original: "I'établissement à Genève d'um Bureau international d'éducation, bureau d'informations et d'études scietifiques don't le besoin se fait universellement sentir".

${ }^{72}$ Hofstetter et al, "Genève dans le contexte international", 125.

${ }^{73}$ Hofstetter et al, "Genève dans le contexte international", 127.

${ }^{74}$ Hameline, L'Éducation dans le miroir du temps, 197.

${ }^{75} \mathrm{~F}$. Vidal, "L'éducation nouvelle et l'esprit de Genève", 86.

${ }^{76}$ Hameline, L'Éducation dans le miroir du temps, 199.
} 
Em 1929, com a integração do IJJR na Universidade de Genebra e a exacerbação do culto à Nação que invadiu os debates educacionais, prenunciando a Segunda Grande Guerra, o BIE assumiu nova configuração, passando a um instrumento intergovernamental neutro, refundado, segundo Hameline, em acordo firmado entre a Polônia, o Peru, 0 Estado de Genebra e o IJJR. Apesar de manter os ideais de defesa da paz, viu reforçado seu papel comparatista. ${ }^{77}$ Assumiram sua direção Jean Piaget e Pedro Rosselhó. ${ }^{78}$ Piaget, por quase 40 anos, ficou à testa do Bureau, dotando-0 de uma maior respeitabilidade científica, ao custo de uma neutralidade política em contextos extremos.

0 IJJR, e a ele associados a Maison des Petits e o BIE, consistiu no local de passagem e de formação de um contingente significativo de educadores de várias partes do mundo, constituindo-se em um importante hub a interligar sujeitos provenientes de diversos países. Como aconteceu com o TC, o Brasil tampouco esteve fora desse circuito. Dois exemplos colhidos na historiografia da educação brasileira podem ser ilustrativos. 0 primeiro refere-se a Laura Jacobina Lacombe, educadora católica, nascida em 1897, no Rio de Janeiro, que em 1925 embarcou para a Europa, com o objetivo de frequentar os cursos promovidos pelo IJJR. ${ }^{79} \mathrm{~A}$ mesma educadora participou do Congresso da NEF/LIEN de Locarno, em 1927, como delegada da Associação Brasileira de Educação (ABE).

Ao retornar ao Brasil, ainda em 1927, Laura Lacombe representou o BIE na Primeira Conferência Nacional de Educação, promovida pela $A B E$, apresentando uma notícia sobre o Bureau, lida na Sessão Plenária. Segundo Marta Carvalho, ${ }^{80}$ a leitura "teria mesmo ensejado a oportunidade de inúmeras novas adesões à instituição suíça, por intermédio de seu então correspondente brasileiro, Lourenço Filho". Não obstante, no relatório de viagem, entregue ao Conselho Diretor da ABE, Lacombe anunciava reservas. Segundo ela,

\footnotetext{
Os princípios da "escola ativa" tão bem estudados pelo Prof. Ferrière nos seus livros, merecem ser aprofundados para serem adotados em nosso país a exemplo do que já fez a Áustria. (...) Verdade é que esses métodos precisam ser adaptados à nossa raça para serem eficientes pois se não forem bem empregados serão até prejudiciais. Se a liberdade não for bem dosada cai-se na anarquia, o que talvez seja pior do que a disciplina antiga. ${ }^{81}$
}

Passados três anos, em 1930, era a vez de Claparède ir ao Brasil e visitar Lacombe no Rio de Janeiro, no âmbito de viagens realizadas, nas palavras de Ana Christina Mignot, ${ }^{82}$ como

\footnotetext{
77 D. Hameline, L'Éducation dans le miroir du temps, 200.

${ }^{78} \mathrm{~F}$, Vidal, "L'éducation nouvelle et l'esprit de Genève", 87.

${ }^{79}$ Ana Chrystina Mignot, "Eternizando travessia: memórias de formação em álbum de viagem", Revista Brasileira de Pesquisa (Auto)biográfica 2, n. 5 (2017): 336.

${ }^{80}$ Marta Carvalho, "A bordo do navio, lendo notícias do Brasil: o relato de viagem de Adolphe Ferrière", en Viagens Pedagógicas, ed. Ana Chrystina Mignot y José Gondra (São Paulo: Cortez Editora, 2007), 289.

${ }^{81}$ Citado por Ana Chrystina Mignot,."Claparède, mestre e amigo: memórias de travessias", Revista Interinstitucional Artes de Educar 2, no. Especial (jun - out 2016): 263.

${ }^{82}$ Mignot, "Claparède, mestre e amigo", 261.
} 
parte das estratégias do Instituto Jean-Jacques Rousseau para estreitar laços, divulgar experiências e estabelecer novos contatos, legitimando-se, deste modo, como um "centro de referência", um "centro de investigações", um "centro de informações" e um "centro de propaganda".

A visita reforçava os laços de amizade constituídos quando da estada da educadora brasileira no IJJR e mantidos por meio de correspondências trocadas com Claparède, sua esposa e Bovet, durante anos.

0 segundo exemplo não parte do Brasil, mas a ele chega. Remete à educadora russa, Helena Antipoff, "aluna e assistente de Claparède no Instituto Jean-Jacques Rousseau, em Genebra, que veio a ser convidada a implantar o Laboratório de Psicologia da Escola de Aperfeiçoamento, e a iniciar o estudo e a pesquisa em psicologia da educação no âmbito da Reforma" ${ }^{33}$ educacional realizada em Minas Gerais, em 1929.

A trajetória de Helena Antipoff acrescenta detalhes ao tramado da circulação internacional de sujeitos educacionais no período. Nascida em Grodno em 1892, estagiou no Laboratório de Psicologia da Universidade de Paris, entre 1909 e 1912, tendo participado dos ensaios de padronização dos testes de nível mental de crianças então elaborados por Alfred Binet e Théodore Simon. De 1912 a 1916, integrou o IJJR, atuando, em 1913, como uma das três professoras da fase inicial da Maison des Petits, como referido anteriormente. Entre 1916 e 1924, voltou a Rússia e, em 1921, trabalhou como colaboradora científica no Laboratório de Psicologia Experimental de Petersburgo, fundado por Aleksandr Petrovich Nechaev. Em 1925, fixou residência em Genebra, sendo assistente de Édouard Claparède no Laboratório de Psicologia da Universidade de Genebra e novamente professora na Maison des Petits. Viajou ao Brasil em 1929, a convite, permanecendo no país até sua morte em 1974.

Ao longo desse percurso hibridizou teorias e mobilizou práticas de modo a compor uma proposta original de educação rural para crianças em exclusão social, implantada na Fazenda do Rosário, a partir de 1940. De acordo com Regina Helena Campos,

A experiência de Antipoff, vivendo, observando e trabalhando em diferentes culturas, evidencia que, em cada situação, a atitude científica representou, para ela, a língua franca de acesso ao novo universo simbólico. Confrontada com a necessidade de adaptação em contextos diversos, sempre a curiosidade científica Ihe aparecia como a porta de entrada, a condição de possibilidade de compreender 0 estranho, e de se fazer compreender. ${ }^{84}$

Laura Lacombe e Helena Antipoff se juntam aos demais casos de viajantes explorados neste texto, a exemplo de Anisio Teixeira e Washburne, passeurs, como se refere Serge Gruzinski ${ }^{85}$ a esses sujeitos que transitam entre culturas e promovem mestiçagens. Nos itinerários traçados, estabeleceram interações pessoais e reposicionaram continuamente

\footnotetext{
${ }^{83}$ Regina Helena de Freitas Campos, "Helena Antipoff: razão e sensibilidade na psicologia e na educação", Estudos avançados [online] 17, no. 49 (2003): 209. A biografia de Antipoff aqui resumida foi colhida majoritariamente neste artigo.

${ }^{84}$ Regina Campos, "Helena Antipoff", 228.

${ }^{85}$ Gruzinki, "Os mundos misturados da monarquia católica".
} 
os pontos de contato, promovendo uma circulação internacional de saberes e práticas educativas em redes e sendo agentes na invenção de histórias múltiplas e inesperadas.

\section{Comentários finais}

Neste ano em que se comemora o centenário da NEF/LIEN, duas questões chamam a atenção. A primeira delas corresponde à compreensão de que os anos 1920 forjaram o núcleo de uma epistemologia ainda presente no campo educacional, na reiteração de propostas como protagonismo infantil, método de projetos, centros de interesse, professor como mediador, educação para democracia, dentre outras, porque constitutivas do embrião da disciplina acadêmica no seio das universidades. Foram pedras angulares do movimento internacional em prol da Educação Nova e continuam como operatórias para as pedagogias que se apresentam como inovadoras e que, em sua maioria, desconhecem as raízes associadas à NEF/LIEN e aos demais hubs aqui mencionados.

A segunda questão consiste no reconhecimento de que algumas historiografias nacionais da educação gestaram obstáculos à percepção dos contornos do movimento internacional de difusão da Educação Nova. Os pesquisadores/as de língua anglófona discorrem sobre a NEF, já os francófonos e oriundos da América Latina remetem à LIEN. As duas entidades emergem em parcela significativa das narrativas como distintas. A não homologia entre as denominações por certo corroborou para a dissociação. No entanto, ao percorrer os relatos da criação da NEF e da LIEN, a identidade dos eventos reafirma a unidade das siglas, o que mantém seu distanciamento é o conjunto dos textos articulados pelas historiografias nacionais da educação na interpretação do fenômeno. Mais um exemplo de que, ao longo do tempo, as ideias ganharam corpo próprio e se distanciaram dos contextos de nascimento. É novamente Hameline ${ }^{86}$ que nos lembra de que NEF e LIEN são apenas nomes diversos de um mesmo movimento.

Iniciativas como o SWG Mapping the discipline, ${ }^{87}$ criado no âmbito da ISCHE poderiam concorrer para desatar as análises de seus contextos locais e superar os constrangimentos da pesquisa em história da educação às comunidades lingüísticas às quais pertencem os/as pesquisadores/as ou às quais têm acesso por competências individuais. 0 estabelecimento de redes multilíngues permitiria não apenas compreender os modos como os debates sobre a Educação Nova foram conformados localmente, mas, principalmente, como se sintonizam a uma agenda mundial que ainda povoa 0 imaginário pedagógico na atualidade.

Por certo, esta pregnância não se deveu unicamente à ação da NEF/LIEN. Outros hubs foram acionados neste texto, de modo a afirmar a concorrência de expressões que 0 movimento internacional em prol da Educação Nova assumiu nas várias instituições que abraçaram a causa. 0 objetivo foi evidenciar as fraturas existentes nesse movimento. Ou-

\footnotetext{
${ }^{86}$ Hameline, L'Éducation dans le miroir du temps, 159.

${ }^{87}$ Rita Hofstetter, Alexandre Fontaine, Solenn Huitric, and Emmanuelle Picard, "Mapping the discipline history of education", Paedagogica Historica 50, no. 6 (2014): 871-880.
} 
tras fraturas, no entanto, não chegamos a mencionar, como 0 estatuto ambíguo conferido a educadores, frequentemente associados à Educação Nova, tais quais John Dewey ou Anísio Teixeira, com a aproximação da Segunda Guerra mundial.

A vaga conservadora que invadiu as discussões pedagógicas às vésperas e durante o conflito armado, especialmente no que tange ao uso das escolas como meio de exacerbar o patriotismo e conquistar a adesão da juventude aos esforços bélicos, entrou em conflito com os ideais pacifistas, de promoção da iniciativa individual e de crítica à educação tradicional, tramados pelo movimento da Educação Nova. Como parte da maquinaria acionada pela guerra, as escolas também foram convocadas a se alinhar à nova ordem. A evidência mais precoce foi o desaparecimento da revista Das Werdende Zeitalter. 0 encerramento das atividades da PEA, em 1955, e do periódico Progressive Education, em 1957, também pode ser creditado a este ocaso do movimento no cenário educacional ${ }^{88}$.

Entretanto, a despeito dos revezes pelos quais passou, a Educação Nova parece ter sobrevivido no repertório pedagógico. Favoreceu-lhe 0 estatuto de fórmula e, possivelmente, sua posição seminal na criação dos Departamentos de Educação associados às Universidades. Seria exagerado dizer que sobreviveu porque utópica? Fato é que 100 anos depois da criação da NEF/LIEN ainda nos referimos à Educação Nova como um ideal a atingir. Talvez por isso, continuemos a investigar e publicar sobre o tema.

\section{Bibliografia}

Aldrich, Richard. "The training of teachers and educational studies: the London Day Training College, 1902-1932”. Paedagogica Historica 40, no. 5-6 (2004): 617-631.

Araújo, Roberta Maira de Melo. “Benedicta Valladares Ribeiro (1905-1989): formação e atuação". Tese de Doutorado, Universidade de São Paulo, 2010.

Barabási, Albert-László. Linked: how everything is connected to everything else and what it means for business, science, and everyday life. New York: Plume, 2003.

Boyd, William, and Wyatt Rawson. The Story of the New Education. London: Heinemann, 1965.

Braster, Sjaak, and María del Mar del Pozo Andrés. "La escuela nueva en imágenes: fotografía y propaganda en The New Era (1920-1939)". Historia y Memoria de la Educación 8 (2018): 97-145.

${ }^{88}$ Caroline J. Conner, and Chara H. Bohan, "The Second World War's impact on the progressive educational movement: Assessing its role", Middle and Secondary Education Faculty Publications 74 (2014). 
Brehony, Kevin J. "A new education for a new era: the contribution of the conferences of the New Education Fellowship to the disciplinary field of education 1921-1938". Paedagogica Historica 40, no. 5-6 (2004): 733-55.

Burke, Peter. História social do conhecimento. Rio de Janeiro: Zahar, 2003.

Campos, Regina Helena de Freitas. "Helena Antipoff: razão e sensibilidade na psicologia e na educação". Estudos avançados [online] 17, no. 49 (2003): 209-31.

Carvalho, Marta. "A bordo do navio, lendo notícias do Brasil: o relato de viagem de Adolphe Ferrière". En Viagens Pedagógicas, editado por Ana Chrystina Mignot e José Gondra. São Paulo: Cortez Editora, 2007.

Chahin, Samira Bueno. "Cidade nova, escolas novas? Anísio Teixeira, arquitetura e educação em Brasília”. Tese de Doutorado, Universidade de São Paulo, 2018.

Conner, Caroline J., and Chara H. Bohan. "The Second World War's impact on the progressive educational movement: Assessing its role". Middle and Secondary Education Faculty Publications 74 (2014): 1-27.

Coquoz, Joseph. "Le Home 'Chez Nous' comme modèle d'attention à l'enfance”. Educació i Història: Revista d'Història de l'Educació, no. 20 (2012): 27-47.

Correia, Luis Grosso. "The right kind of education for the right individual: comparative education studies according to the Educational Yearbook of the Teachers College (1924-1944)". History of Education 40, no. 5 (2011): 577-598.

Cremin, Lawrence, David A. Shannon, and Mary Evelyn Townsend. A history of Teachers College Columbia University. Nova Iorque: Columbia University Press, 1954.

Cury, Carlos Roberto. "Anisio Teixeira (1900-1971)". Prospects: the quarterly review of comparative education XXX, no. 4 (2000): 509-20.

Fonseca, Nelma Marçal. "Alda Lodi, entre Belo Horizonte e Nova lorque: um estudo sobre formação e atuação docentes 1912-1932". Dissertação de Mestrado, Universidade Federal de Minas Gerais, 2010.

Fonseca, Silvia Assam da. "A coleção Bibliotheca do espírito moderno: um projeto para alimentar espíritos da Cia. Editora Nacional (1938-1977)". Tese de doutorado, Pontifícia Universidade Católica de São Paulo, 2010.

Fuchs, Eckhardt. "Networks and the History of Education". Paedagogica Historica 43, no.2 (2007):185-97. 
Graham, Patricia Albjerg. Progressive Education: from arcady to academe. A history of the Progressive Education Association, 1919-1955. New York: Teachers College Press, 1967.

Graham, Patricia Albjerg. "Carleton Wolsey Washburne: a biographical essay". Teachers College Record 72, no. 6 (1971): 487-494.

Gruzinski, Sege. "Os mundos misturados da monarquia católica e outras connected histories". Topoi (2001): 175-95.

Hameline, Daniel L'école active. Textes fondateurs. Paris: PUF, 1995.

Haenggeli-Jenni, Béatrice. L'Éducation nouvelle entre science et militance: débats et combats à travers la revue Pour l'Ère Nouvelle (1920-1940). Bern: Peter Lang, 2017.

Hameline, Daniel. "Aux origins de la Maison des Petitis". En Une école où les enfants veulent ce qu'ils font; La Maison des Petits hier et aujourd'hui, editado por Christiane Perregaux, Laurence Rieben et Charles Magnin, 17-62. Lausanne: Société coopérative des Editions des Sentiers, 1996.

Hameline, Daniel. L'Éducation dans le miroir du temps. Lausanne: Société coopérative des Editions des Sentiers, 2002.

Hofstetter, Rita. "The construction of a New Science by means of na institute and its communication media: the institute of educational sciences in Geneva (1912-1948)". Paedagogica Historica 40, no. 5-6 (2004): 657-683.

Hofstetter, Rita, and Bernard Schneuwly. "Contrasted views of New Education on knowledge and its transformation. Anticipation of a new mode or ambivalence?". Paedagogica Historica 45, no. 4-5 (2009): 453-467.

Hofstetter, Rita, Alexandre Fontaine, Solenn Huitric, and Emmanuelle Picard. "Mapping the discipline history of education”. Paedagogica Historica 50, no. 6 (2014): 871-880.

Hofstetter, Rita, Bernard Schneuwly, Valérie Lussi, and Béatrice Haenggeli. "Genève dans le contexte international". En Passion, fusion, tension. New Education and Educational Sciences. Editado por Rita Hofstetter e Bernard Schneuwly, 107-142. Berne. Peter Lang, 2006.

Jenkins, Celia M. "The professional middle class and the social origins of progressivism: a case study of the New Education Fellowship, 1920-1950". Tese de doutorado, University of London, 1989. 
Lawn, Martin. "Um conhecimento complexo: o historiador da educação e as circulações transfronteiriças". Trad.: Rafaela Silva Rabelo. Revista Brasileira de História da Educação 14, no. 1 (2014): 127-144.

Lawson, M. D. "The New Education Fellowship: the formative years". Journal of Educational Administration and History 13, no. 2 (1981): 24-28.

Magnin, Charles, and Rita Hofstetter. "Education nouvelle et changements éducatifs: éléments de définition et pesées d'une influence". Paedagogica Historica 42, no. 1-2 (2006): 1-14.

Mata, Joan Soler. “Entre Europa i América Llatina: Adolphe Ferrière i l'Escola Nova a Barcelona". Temps d'Educació, no. 35 (2008):229-48.

McCullock, Gary. "Fred Clarke and the internationalisation of studies and research in education”. Paedagogica historica 50, no. 1-2 (2014): 123-137.

Middleton, Sue. "Clare Soper's hat: New Education Fellowship correspondence between Bloomsbury and New Zealand, 1938-1946". History of Education 42, no. 1 (2013): 92-114.

Middleton, Sue. "New Zealand Theosophists in 'New Education' networks, 1880s-1938”. History of Education Review 46, no. 1 (2017): 42-57.

Mignot, Ana Chrystina. "Claparède, mestre e amigo: memórias de travessias". Revista Interinstitucional Artes de Educar 2, no. Especial (jun - out 2016): 253-265.

Mignot, Ana Chrystina. "Eternizando travessia: memórias de formação em álbum de viagem”. Revista Brasileira de Pesquisa (Auto)biográfica 2, no. 5 (2017): 330-42.

Nunes, Clarice. Anísio Teixeira: a poesia da ação. Bragança Paulista: EDUSF, 2000.

Portugal, Silvia. "Contributos para uma discussão do conceito de rede na teoria sociológica". Oficina do CES n² 271, Março, 2007.

Pozo Andrés, María del Mar del. "The transnational and national dimensions of pedagogical ideas: the case of the project method, 1918-1939". Paedagogica Historica 45, nos. 4-5 (2009): 561-584.

Pozo Andrés, María del Mar del. "0 Método de Projetos na Espanha: recepção e apropriação (1918-1936)". En Movimento Internacional da Educação Nova, editado por Diana Gonçalves Vidal e Rafaela Silva Rabelo, 189-208. Belo Horizonte: Fino Traço, 2020. 
Rocha, Ana Cristina Matos. "Experiências norte-americanas e projetos de educação no Distrito Federal e em São Paulo (1927-1935): Anísio Teixeira, Noemi Silveira, Isaías Alves e Lourenço Filho". Tese de Doutorado, Fundação Oswaldo Cruz, 2016.

Rabelo, Rafaela Silva. "Isaac Kandel e a constituição de redes entre Brasil e Estados Unidos”. Revista de Ciências da Educação 21, no. 43 (2019): 67-96.

Rabelo, Rafaela Silva. "0 ensino de matemática em um número especial da revista The New Era, 1934". Bolema 33, no. 65 (2019): 1109-1132.

Rabelo, Rafaela Silva. "The New Education Fellowship, the Progressive Education Association, and the US Department of State: South America as part of a complex entanglement". Paedagogica Historica 57, no. 1-2 (2021): 183-199. D0l: https:// doi.org/10.1080/00309230.2021.1872660.

Rabelo, Rafaela Silva, and Diana Gonçalves Vidal. "A seção brasileira da New Education Fellowship: (des)encontros e (des)conexões". En Movimento Internacional da Educação Nova, editado por Vidal e Rabelo. Belo Horizonte: Fino Traço, 2020.

Subrahmanyam, Sanjay. Comércio e conflito. A presença portuguesa no Golfo de Bengala, 1500-1700. Lisboa: Edições 70, 1994.

Students from Latin American Countries Registered in Teachers College, Columbia University, 1920-1940. Pocketknowledge, Gottesman Libraries, Teachers College, Columbia University.

Vidal, Diana. 0 exercício disciplinado do olhar: livros, leituras e práticas de formação docente no Instituto de Educação do Distrito Federal (1932-1937). Bragança Paulista: Editora da Universidade São Francisco, 2001.

Vidal, Diana Gonçalves, and Rafaela Silva Rabelo. "A criação de Institutos de Educação no Brasil como parte de uma história conectada da formação de professores". Cadernos de História da Educação 18, no. 1 (2019): 208-220.

Vidal, Diana, Rafaela Rabelo, Ariadne Ecar, and Fernanda Franchini. "Democracia, escola e infância: legado e utopia escolanovista". Em Democracia, escola e infância, editado por Carlota Boto, Julio Groppa Aquino, 107-122. São Paulo: FEUSP, 2019.

Vidal, Fernando. "L'éducation nouvelle et l'esprit de Genève”. Equinoxe, no. 17 (1997): 81-98.

Watras, Joseph. "The New Education Fellowship and UNESCO's programme of fundamental education”. Paedagogica historica 47, no. 1-2 (2011): 191-205. 